\title{
Progresso da Brusone nas Folhas no Plantio Direto e Convencional de Arroz de Terras Altas*
}

\author{
Gisele B. da Silva ${ }^{1} \&$ Anne S. Prabhu ${ }^{2}$ \\ ${ }^{1}$ Escola de Agronomia, Universidade Federal de Goiás, Cx. Postal 131, CEP 74001-970, Goiânia, GO, \\ e-mail: gibarata@ bol.com.br; ${ }^{2}$ Embrapa Arroz e Feijão, Cx. Postal 179, CEP 75375-000, Santo Antônio de Goiás, GO, \\ fax: (062) 533-2100, e-mail: prabhu@cnpaf.embrapa.br
}

(Aceito para publicação em 27/06/2003)

Autor para correspondência: Gisele Barata da Silva

SILVA, G.B. \& PRABHU, A.S. Progresso da brusone nas folhas no plantio direto e convencional de arroz de terras altas. Fitopatologia Brasileira 29:316-318. 2004.

\section{RESUMO}

Foram estudados o progresso da brusone (Pyricularia grisea) e o conteúdo de clorofila nas folhas em experimentos de campo, com arroz (Oryza sativa) de terras altas, nos sistemas de plantio direto (PD) e convencional (PC), durante as safras de 1998/1999 e 1999/ 2000. As taxas aparente de infecção da brusone nas folhas na primeira safra no PC e no PD formam de $b=0,099(\mathrm{r}=0,97 * *)$ e de $\mathrm{b}=$ $0,066\left(\mathrm{r}=0,90^{* *}\right)$, respectivamente. Na segunda safra foram de $\mathrm{b}=$ $0,054(\mathrm{r}=0,99 * *)$ no PC e no PD de $\mathrm{b}=0,055(\mathrm{r}=0,99 * *)$. Entretanto as taxas de progresso da brusone nas folhas não diferiram estatisticamente nos dois sistemas de plantio. Foi observada uma relação linear, positiva e significativa entre conteúdo de clorofila e a severidade da brusone nas folhas.

Palavras-chave adicionais: Pyricularia grisea, Oryza sativa, epidemiologia, sistema de cultivo.

\section{ABSTRACT}

Leaf blast progress in direct and conventional drilling of rice under upland conditions

The disease progress of leaf blast (Pyricularia grisea) and chlorophyll leaf content in upland rice (Oryza sativa) were studied under direct drilling (DD) and conventional drilling (CD), in field experiments during 1998/1999 and 1999/2000. The apparent infection rates of leaf blast for CD and DD were $b=0.099(r=$
$0,97 * *)$ and $\mathrm{b}=0.666(\mathrm{r}=0,90 * *)$ respectively, in the first growing season. In the second season, the rates for CD and DD were $\mathrm{b}=$ $0.054(\mathrm{r}=0,99 * *)$ and $\mathrm{b}=0.05(\mathrm{r}=0,99 * *)$. However, there was no significant difference in the rates of leaf blast progress in these two tillage systems. A linear, positive and significant relationship was observed between the chlorophyll content of the leaf and leaf blast severity.
O arroz (Oryza sativa L.) de terras altas é tradicionalmente cultivado em áreas extensivas em todos os Estados do Centro-Oeste. As mudanças na agricultura brasileira do sistema de cultivo de arroz de terras altas como desbravador do cerrado para a implantação de pastagens, para um sistema com o uso de grande quantidade de insumos e mecanização, estão associadas às condições que favorecem uma elevada incidência de doenças, principalmente da brusone causada por Pyricularia grisea (Cooke) Sacc.

O plantio direto (PD) caracteriza-se por ser uma das práticas agrícolas mais eficientes no controle da erosão de solos (Phillips, 1993). A palha deixada sobre a superfície do solo altera o microclima e influencia diretamente os processos biológicos que ocorrem neste ambiente (Fernandes, 1997). Nas camadas superiores do solo, é encontrada maior quantidade de microorganismos em função da maior concentração de palhada e da elevada concentração de $\mathrm{C} / \mathrm{N}$ quando comparada ao plantio convencional (PC) (Almeida, 1985). Fitopatógenos que sobrevivem nessas condições dispõem de eficiente inóculo e podem causar elevada incidência de doença na cultura subsequente (Reis, 1995).

A brusone causa danos significativos no PC, princi- palmente em lavouras onde não é utilizado o controle químico, devido à suscetibilidade nas cultivares melhoradas para qualidade de grãos. A infecção das folhas é responsável por perdas indiretas devido à redução da área foliar fotossintetizante. A brusone não somente reduz a quantidade da área foliar verde, mas também reduz a atividade fotossintética do tecido circundante à lesão (Bastiaans, 1991).

O progresso da doença em relação ao tempo é importante para descrever a epidemia e não existe informações comparando os sistemas de plantio direto e convencional de arroz de terras altas. Os conhecimentos quanto ao progresso da brusone no PD em relação ao PC fornecem subsídios para o uso de maior ou menor quantidade de fertilizantes nitrogenados e fungicidas no manejo desta doença com o intuito de minimizar seu efeito na produtividade e na qualidade dos grãos. No presente trabalho foram estudados o progresso da brusone nas folhas e a relação entre o conteúdo de clorofila no PD e no PC.

Os experimentos de campo, realizados para estudar a influencia de práticas culturais sobre a brusone nas folhas e nas panículas nos sistema de PD na palha e PC foram utilizados para analisar o progresso da brusone nas folhas. Os experi- 
Progresso da brusone nas folhas no plantio direto e convencional...

mentos foram conduzidos com as cultivares Primavera e Carajás na safra 1998/1999, com área de 1344 m², em cada sistema de plantio e, repetidos na safra 1999/2000, com área de $448 \mathrm{~m}^{2}$ por sistema de plantio, na Fazenda Capivara, Embrapa Arroz e Feijão. Na safra de 1998/1999 a severidade da brusone nas folhas foi avaliada tomando-se ao acaso 32, 20 e 16 perfilhos e contando-se o número de lesões abertas nas três últimas folhas abertas, aos 55, 64 e 85 DAP, respectivamente. Na safra de 1999/2000 a severidade foi avaliada tomando-se ao acaso 20 perfilhos, aos 48, 52, 55 e 59 DAP e determinando-se a porcentagem da área foliar afetada pela doença nas últimas quatro folhas abertas, de acordo com uma escala diagramática com dez graus (Notteghem, 1981). A taxa aparente de infecção da brusone nas folhas (b) em relação ao tempo no PD e no PC foi determinada pelo método de regressão linear, após a transformação dos dados de severidade da brusone em proporção para logito, de acordo com Van der Plank (1963), considerando a média de 24 observações, oito tratamentos e três repetições na primeira safra e 32 observações, oito tratamentos e quatro repetições na segunda safra. A extrapolação da quantidade de inóculo inicial foi feita utilizando a fórmula $\log (\mathrm{Y} /(1-\mathrm{Y}))$ - b . t (Berger, 1977), onde y é a severidade da doença, b é a taxa aparente de infecção e t é a duração da epidemia. O coeficiente de determinação, o quadrado médio e a dispersão independentes dos erros foram utilizados para selecionar o modelo da epidemia.

O teor de clorofila, nas duas safras, foi determinado em 20 perfilhos na última folha aberta com o aparelho Minolta SPAD-502 posicionado no terço superior da folha. A análise foi feita para estabelecer a relação entre o teor de clorofila e a severidade de brusone nas folhas aos 55 DAP e 48 DAP, nas safras 1998/1999 e 1999/2000, respectivamente.

O progresso da brusone nas folhas em relação ao tempo no PD e PC, nas duas safras, encontra-se na Figura 1. As taxas aparente de infecção da brusone nas folhas na primeira safra no PC e no PD forma de $b=0,099$ e de $b=0,066$, respectivaente. Na segunda safra foi de $b=0,054$ no PC e no $\mathrm{PD}$ de $\mathrm{b}=0,055$. Entretanto não houve diferenças significativas entre as taxas aparentes de infecção da brusone nas folhas nos dois sistemas de plantio pelo teste de $\mathrm{t}$ entre $\mathrm{t}$ $=1,04^{\text {ns }}$ e $\mathrm{t}=0,016^{\text {ns }}$ ) nas duas safras avaliadas. Para se obter um nível de doença final no PC semelhante ao PD, aos 85 DAP, é necessário uma redução do inóculo inicial no PC de 2 x $10^{-3}$ para 2,6 x $10^{-4}$, correspondendo a uma redução em 100 vezes, no ano 1998/99 (Figura 1). Na safra de 1999/2000, a redução do inóculo inicial no PC deve ser de $8,8 \times 10^{-3}$ para $3,7 \times 10^{-4}$, correspondendo a 500 vezes menos aos 59 DAP (Figura 1). Esta redução de inóculo inicial pode ser obtida pela resistência vertical da cultivar e pela sanidade da semente. É importante ressaltar que após esse período da fase vegetativa, a folha adquire resistência à brusone, devido a silicificação da parede celular com o aumento da idade da planta (Prabhu \& Filippi, 1995). Uma determinada quantidade de inóculo inicial, não necessariamente resulta em uma severidade elevada da doença, porque vários outros fatores como temperatura,
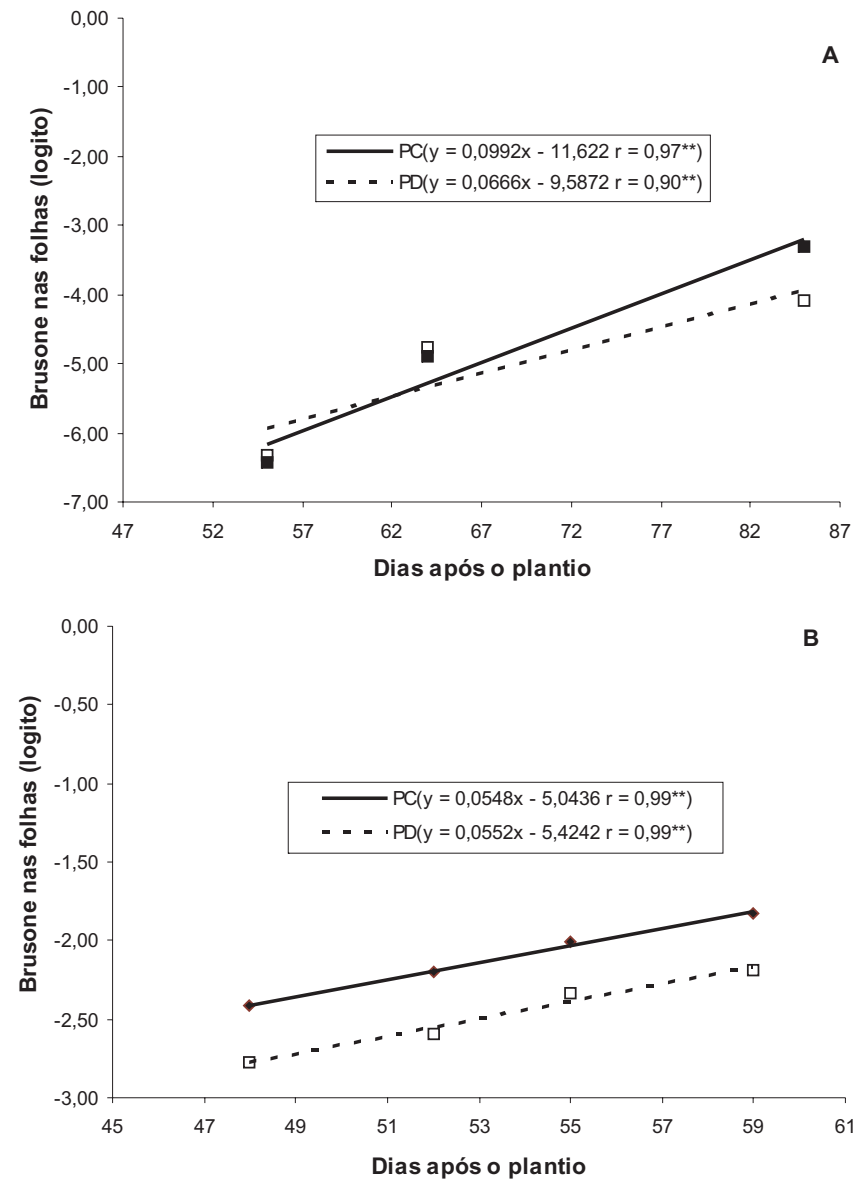

FIG. 1 - Progresso da brusone (Pyricularia grisea) nas folhas de arroz (Oryza sativa) nos plantio direto (PD) e no plantio convencional (PC) nas safras de 1998/1999 (A) e 1999/2000 (B). (Cada ponto representa média de 24 observações em (A) e 32 em (B)).

adubação nitrogenada, resistência da cultivar entre outros, influenciam a eficiência do inóculo inicial (Fry, 1982).

A relação entre a severidade da brusone nas folhas e o conteúdo de clorofila é apresentada na Figura 2. Com o aumento do conteúdo de clorofila a severidade da brusone aumentou significativamente de maneira linear e positiva no PD e no PC, nas duas safras. A determinação do estado nutricional da planta em relação ao nitrogênio, utilizando o clorofilômetro, é um método simples, mas a relação entre concentração de nitrogênio e valores de clorofila difere dependendo do estágio fenológico da cultivar (Peng et al., 1993). O clorofilômetro constitui-se em uma ferramenta para estimar o teor de clorofila nas folhas evitando assim a análise por métodos convencionais de $\mathrm{N}$ como Kjeldahl, que é um método destrutivo e oneroso. A avaliação da clorofila com SPAD Minolta-502 é simples e rápida, sendo realizada em plantas intactas sob condições de campo. Este aparelho foi utilizado com sucesso para determinar o conteúdo de clorofila nas diferentes culturas inclusive o arroz (Watanabe et al., 1980; Peng et al., 1993). São necessários estudos mais detalhados para determinar os níveis de $\mathrm{N}$ adequados para 

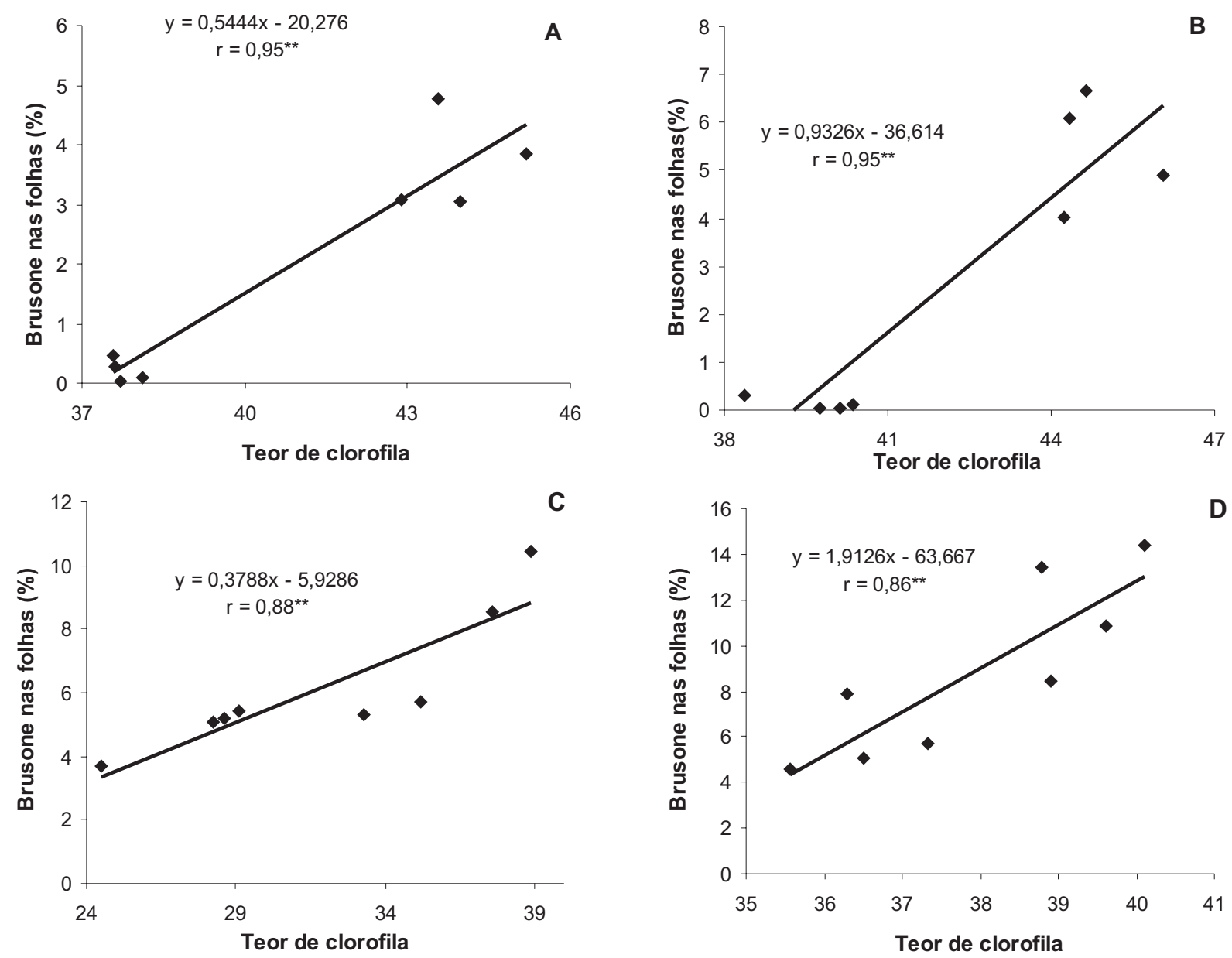

FIG. 2 - Relação entre o teor de clorofila e a severidade da brusone (Pyricularia grisea) nas folhas de arroz (Oryza sativa) no plantio direto (AC) e convencional (B-D) nas safras 1998/1999 e 1999/2000. (Cada ponto representa média de 24 observações em (A-B) e 32 em (C-D)).

adubação de cobertura em arroz de terras altas considerando os valores de clorofila e sua relação linear com a brusone nas folhas.

\section{REFERÊNCIAS BIBLIOGRÁFICAS}

ALMEIDA, F.S. Influência da cobertura morta do plantio direto na biologia do solo. In: Fancelli, A.L., Torrado, P.V. \& Machado, J. (Eds.) Atualização em plantio direto. Campinas, Fundação Cargill. 1985. pp.103-144.

BASTIAANS, L. Ratio between virtual and visual lesion size as a measure to describe reduction in leaf photosynthesis of rice due to leaf blast. Phytopathology 81:611-615. 1991.

BERGER, R.D. Application of epidemiologycal principles to achieve plant disease control. Annual Review of Phytopathology 15:165-183. 1977.

FERNANDES, J.M.C. As doenças das plantas e o sistema plantio direto. Revisão Anual de Patologia de Plantas 5:317-352. 1997.

FRY, W.E. Epidemiology: dynamics of interacting pathogen and host populations. In: Fry, W.E. (Ed.). Principles of plant management. New York, Academic Press. 1982. pp.43-65.
NOTTEGHEM, J.L. Cooperative experiment on horizontal resistance to rice blast. In: Blast and upland rice: report and recomendation from the meeting for international collaboration in upland rice improvement. Los Baños, IRRI. 1981. pp.43-51.

PENG, S., GRACÍA, F.V., LAZA, M.R.C. \& CASSMAN, K.G. Adjustment for specific leaf weight improves chlorophyll meter's estimate of rice leaf nitrgen content. Agronomy Journal 85:987-990. 1993.

PHILLIPS, S.H. No tillage-past, present and future. In: Simpósio Internacional sobre Plantio Direto em Sistemas Sustentáveis, Fundação ABC. 1993. pp.9-12.

PRABHU, A.S. \& FILIPPI, M.C. Age mediated resistance and fungicide application for leaf blast control for upland rice. International Journal of Pest Management 41:8-13. 1995.

REIS, E.M. Interações entre doenças de cereais de inverno e de milho com sistema plantio direto. Resumos, $1^{\circ}$ Seminário Internacional do Sistema Plantio Direto, Passo Fundo, RS. 1995. pp.63-65.

Van der PLANK, J.E. Plant diseases: epidemics and control. New York, Academic Press. 1963.

WATANABE, S., HATANAKA, Y. \& INADA, K. Development of digital chlorophyllmeter: I. Struture and performance. Japanese Journal of Crop Sciences 49:89-90. 1980 